\title{
EL ESPACIO PICTÓRICO EN LA IMAGEN CINEMATOGRÁFICA: RELACIONES E INFLUENCIAS DEL TROMPE L'OEIL EN EL CINE
}

\section{THE PICTORIAL SPACE IN THE CINEMATOGRAPHIC IMAGE: RELATIONS AND INFLUENCES OF TROMPE L'OEIL IN CINEMA}

\author{
CARlos Rojas-Redondo \\ Grupo de investigación HUM-447: Arte, Técnica y Sostenibilidad \\ rrcarlos20@gmail.com \\ PACO LARA-BARRANCO \\ Universidad de Sevilla. España \\ paco_lara@us.es
}

\begin{abstract}
El objetivo de este artículo es contribuir a los estudios sobre la relación e influencias de la pintura en el cine. Tomando la pintura como referente, medio y punto de intercambio entre la imagen pictórica y cinematográfica, la investigación analiza el espacio como lugar de encuentro de ambas disciplinas, recorre las etapas de relación y conformación de la imagen pictórica para el cine, pasa por el trompe l'oeil como engaño visual, y desemboca en la disyuntiva entre la tarea del pintor de caballete y la de su homónimo en el cine. Hacemos uso de una metodología analítico-comparativa, y nuestra principal conclusión subraya la clara influencia de la pintura en el cine, como entidad de significado fuera de la pantalla.

Palabras clave: pintura; cine; espacio; imagen; engaño visual.
\end{abstract}

The objective of this paper is to contribute to the studies on the relation and influences of painting in cinema. Taking painting as a reference, medium and point of exchange between the pictorial and cinematographic image, the research analyses the space as a meeting place of both disciplines, goes through the stages of relationship and conformation of the pictorial image for the cinema, passes through the trompe l'oeil as a visual deception, and leads to the dilemma between the work of the easel painter and that of his homonym in the cinema. We make use of an analytical-comparative methodology, and our main conclusion underlines the clear influence of painting on film, as an entity of meaning off-screen.

Keywords: painting; cinema; space; image; visual deception. 


\section{INTRODUCCIÓN}

Este artículo pretende analizar las relaciones e influencias de la pintura sobre el cine, haciendo hincapié en su funcionalidad, su concepción estructural como creación de la imagen y su intencionalidad como ente aislado. A partir de lo anterior nuestra investigación pretende ofrecer una visión generalizada de la presencia de la pintura en el cine como creación artística, y estudiar cómo se constituye para lograr alcanzar los fines que se propone.

Con el apartado El espacio en la imagen cinematográfica y pictórica, abordamos las diferencias de la representación del espacio: frente a una imagen centrípeta en la pintura surge la imagen centrífuga en el cine, así como las influencias que el cine ha recibido de la pintura. En el apartado La imagen pictórico-cinematográfica, pretendemos conocer el cómo, esto es, la manera en que se genera la imagen pictórica para el cine a partir de sus propias características y las relaciones que pueden surgir de forma recíproca a partir de la presencia de la pintura, en un amplio abanico, en el filme. En el apartado El trompe l'oeil: falsa evidencia en la pintura y el cine, buscamos dar muestra de la utilización de un engaño a los sentidos por medio de la pintura para satisfacer el deseo visual y recrear realidades, que compitan con su real, erigiéndose como originales y no como copias. Finalmente, en el apartado Pintor-pintor versus pintor-cinematográfico, pretendemos remarcar la labor de un profesional que, distanciándose de sus pulsiones como artista, debe limitar su trabajo exclusivamente en crear para el "ojo" de la cámara. La metodología, sustentada en referencias bibliográficas destacables, ha sido de carácter analítico-comparativa. Por último, las conclusiones del estudio vienen a resaltar la importancia de la pintura como vínculo de conexión continua con el cine, su función como acompañante escenográfico-ambiental y su configuración como realidad de significado, aun quedando relegada en la escena a un plano secundario.

\section{EL ESPACIO EN LA IMAGEN CINEMATOGRÁFICA Y PICTÓRICA}

Buscar nuevas formas de representar el espacio ha sido una constante para tratar de dominarlo mediante la simulación o su exhibición de desnudez más extrema -referido a los espacios vacíos de creaciones digitales proyectadas sobre fondos Croma-. Ya decía André Bazin que, transformando la fórmula de Henri Gouhier, "la escena acepta todas las ilusiones, salvo la de la presencia", y podría decirse que "la imagen cinematográfica puede vaciarse de todas las realidades excepto una: la del espacio"1. Un espacio que mencionaba Leon Battista Alberti en 1436, en relación a la pintura, como "una ventana abierta al mundo" y que con la llegada del cine "pareció ajustar como un guante al nuevo medio, y si la pintura

${ }^{1}$ BAZIN, André: ¿Qué es el cine? Madrid, 2004, pp. 185-186. 
era una ventana, el cine era ya un mirador con asiento preferente, que permitía ver mucho más allá del marco"2. La técnica fílmica permite, como expone David Hockney, no sólo "dibujar en el espacio, sino también en el tiempo [...]. El tiempo, en cierto modo, crea el espacio"3. Este no se puede evitar, eliminar, deshacer de su existencia, puesto que "nunca es neutro en el cine, ni siquiera cuando pretende serlo. Igual sucede en la pintura: el fondo neutro no es, en realidad neutro, desde el momento en que posee materialidad cromática"4. Pero sí podemos afirmar que se delimita su extensión a través del marco, que hace "que la imagen no sea ni infinita ni indefinida, lo que termina, lo que detiene la imagen", , ya que entre pintura y cine el marco diferencia el aspecto de su visualización, siendo la imagen pictórica centrípeta -la representación se consume dentro del marco-, y la imagen cinematográfica centrígufa -se expande fuera de los límites del marco, referenciando un fuera de campo y la observación de un solo fragmento de espacio- ${ }^{6}$. Esta unión-desunión que se produce contempla un intercambio dialógico en el plano cuadro provocando una "ambivalencia, discurso a dos voces, mezcla inestable entre lo alto, la pintura, y lo bajo, el cine, entre el movimiento, el plano, y la inmovilidad, el cuadro"7.

La pintura, en este sentido, corre el riesgo de parecer inmóvil, debido a que el movimiento despliega toda su idiosincrasia en un espacio-tiempo que reduce a la elección de un instante, a punto de producirse, la esencia de la pintura, no ocupándose esta del tiempo. Un instante exacto, el más pregnante, ese que no volverá nunca a suceder, ese que mencionaba Heráclito de Éfeso aludiendo a la universalidad del cambio: "no te podrás sumergir dos veces en el mismo río" 8 . Cuando un artista genera una imagen sobrepasa su pensamiento, que nos remite a ese instante, elemento efímero mental, que transporta al absolutismo de la imagen. Pero esta imagen pictórica, según Paul Klee, "no debe dibujar lo visible, pero debe transformar la expresión subjetiva en algo visible", así como en su campo escenográfico Josef Svoboda expone que "la escenografía no puede ser naturalista, porque precisamente son los detalles naturales los que no pueden ser copiados"

${ }^{2}$ ORTIZ, Áurea: Del cuadro al encuadre: la pintura en el cine: ciclo de cine. Valencia, 2007, p. 17.

${ }^{3}$ HOCKNEY, David: David Hockney: el gran mensaje. Conversaciones con Martin Gayford. Madrid, 2011, p. 234.

${ }^{4}$ GARCÍA, Francisco y PAVÉS, Gonzalo: Ciudades de cine. Madrid, 2014, p. 11.

5 AUMONT, Jacques: El ojo interminable: cine y pintura. Barcelona, 1997, p. 81.

${ }^{6}$ ORTIZ, Áurea y PIQUERAS, María Jesús: La pintura en el cine: cuestiones de representación visual. Barcelona, 2003, pp. 35-36.

${ }^{7}$ BONITZER, Pascal: Desencuadres: cine y pintura. Buenos Aires, 2007, p. 30.

8 KIRK, Geoffrey; RAVEN, John y SCHOFIELD, Malcolm: Los filósofos presocráticos. Madrid, 2008, p. 247.

9 PEDREIRA, Luis Diego: La escenografía. Buenos Aires, 1977, p. 1. 
Es una constante a lo largo de la historia de la pintura, y en su vinculación con la técnica teatral, el interés por captar la naturaleza para estimular al espectador, notándose la influencia de la pintura de escenarios teatrales sobre la de caballete $^{10}$. Y ni que decir tiene, que a pesar del poder sugestivo que tiene la pintura y su versatilidad, se le atribuían intereses económicos por su bajo coste frente a decorados fastuosos y naturalistas, de ahí su utilización en la plástica escénica, especialmente tras el periodo barroco, y sirviendo como muestrario para telones de fondo escenográficos.

Esta utilización de la pintura como reflejo de una época es también empleada en el cine; así lo formuló el director ruso Andrei Tarkovski haciendo de un cuadro la clave de su film Solaris (1972) o Peter Greenaway con La ronda de noche (2007) (Figura 1), en el que a través de los rasgos más característicos de Rembrandt reproduce su más fiel estilo cuando "recurre frecuentemente al tableau vivant, dentro de un efectismo absolutamente barroco, y al fotograma congelado que remite a muchos lienzos del creador. Toda la película es pura visualidad y crea espacios teatrales, con los que las barreras entre cine, pintura y teatro se difuminan"11.

Greenaway afronta el cine como si lo hubieran inventado los pintores, y es que podríamos tildarlo de pintar la luz, pero no al estilo dramático escenográfico con el que se reforzaban las sombras de relieves o salientes, los peldaños de escaleras para diferenciar la huella de la contrahuella o la acentuación de la luz con el color en zonas convexas, sino a la manera que declara José Enrique Monterde: "Pintar la luz equivale a pintar el tiempo"12. Y eso que Maurizio Calvesi recriminaba a algunos directores de cine el uso que hacían de la pintura, puesto que provocaba en el espectador una gran incongruencia entre la apariencia fija y mentalmente móvil de la pintura, y viceversa en el cine. O como lo pronuncia Antonio Costa: "la pintura define el límite donde el cine termina, porque la pintura es la «infranqueable frontera» que la puesta en escena cinematográfica no puede alcanzar"13.

El cine y la pintura no representan de igual manera el espacio y el tiempo, aunque como señala Yuri Tynianov, "por su material, el cine está cerca de las artes plásticas, de las artes espaciales, es decir, de la pintura. Por su desarrollo, se acerca a las artes temporales, a la literatura y la música"14. Es innegable la influencia de la pintura sobre el cine, desde los métodos de iluminación hasta las

${ }^{10}$ ARREGUI, Juan: Los arbitrios de la ilusión: los teatros del siglo XIX. Madrid, 2009, p. 67.

${ }^{11}$ CAMARERO, Gloria: Pintores en el cine. Madrid, 2009, p. 108.

${ }_{12}$ MONTERDE, José Enrique: "El sol del membrillo", Archivos de la Filmoteca, 13, 1992, p. 128.

${ }_{13}$ COSTA, Antonio: Cinema e Pittura. Turín, 1993, p. 177.

${ }^{14}$ ALBERA, François: Los formalistas rusos y el cine. La poética del filme. Barcelona, 1998 , p. 82. 
disposiciones ambientales, de ahí que se complementen, mediante influjos recíprocos y se van conformando en su propia evolución. Eisenstein defendía que "el cine es la etapa contemporánea de la pintura"15, y Marcel Martin que "la historia y estética del cine es un compendio de la de la pintura" ${ }^{16}$.

Por tanto, pretendemos conocer el uso que se ha hecho de la pintura en el cine a través de diferentes técnicas, las tipologías de trucos artístico-visuales y la evolución sufrida a lo largo de los años. Quizás, no sea necesario llegar al extremo de Oscar Freedburg cuando afirmaba que disfrutaba de las películas únicamente como pinturas para admirar o captar el uso que se hace de esta en el medio cinematográfico. Pero sí hacer del movimiento que se produce ante nuestros ojos un intento por saber mirar entendiendo a través del medio artístico, como expone Jacques Aumont: "En este esfuerzo para, a la vez, atrapar el momento que huye y comprenderlo como momento fugitivo y cualquiera [...] lo que se constituye es el ver: una nueva confianza en la vista como instrumento de conocimiento, y por qué no, de ciencia"17. Aunque una cosa sí parece clara: como se dice en China, para pintar hacen falta tres elementos, "la mano, el ojo y el corazón, solo dos no sirven" $"$, y el cine y la pintura lo comparten en su totalidad.

\section{LA IMAGEN PICTÓRICO-CINEMATOGRÁFICA}

El cine es un juego de luces y sombras, desarrollado en un espacio para albergar algo diferente, íntimo, sugestivo, que puede transformarse en algo extraordinario. Germén Gelpi define el encuadre como "el libro dividido en tomas y secuencias, es el libreto transformado en escrito llevado a imágenes, donde figuran planos de tomas, diálogos, explicaciones técnicas, especificaciones para sonido, escenografía, luz y cámaras" ${ }^{19}$. Encuadrar es estar dentro de la visión del artista, de la mente del cineasta, y a la misma vez escoger un fragmento de la realidad para excluir el resto, mientras se enfrenta a la disyuntiva entre lo mostrado y lo que se oculta.

Esta elección divide el espacio y lo secciona, haciendo del campo y el fuera de campo una necesidad ingente para la continuidad narrativa de la historia. Un campo que delimita el marco cinematográfico, y a su vez apunta a ese fuera de campo, ausente ópticamente, que completa el espacio imaginario y el espectador sabe que está aunque ante sus ojos no se muestre, por esa característica centrífuga de la que hablábamos. Así, "ambos, campo, manifiesto visualmente, y fuera

${ }^{15}$ CERRATO, Rafael: Cine y pintura. Madrid, 2009, p. 24.

16 Ibidem, p. 36.

17 AUMONT, Jacques: El ojo interminable: cine y pintura..., op. cit., pp. 41-43.

18 HOCKNEY, David: David Hockney: el gran mensaje. Conversaciones con Martin Gayford..., op. cit., p. 62.

${ }^{19}$ GELPI, Germen: La escenografía en el cine. Buenos Aires, 1968, p. 32. 
de campo, sugerido, constituyen un mismo espacio, ambivalente y homogéneo, el espacio fílmico. Espacio que se constituye como discurso o texto, puesto que se funda en una relación significante"20.

El encuadre nos traslada a su estrecha relación con la escenografía, genera fugas o compensación de masas, establece la atmósfera necesaria, hace que, en el caso de que no exista, se encargue él mismo de crearla. Por tanto, encuadrar remite a un sentido bidimensional, de valor cuantitativo, de acotación y selección de la materia filmable, utilizando un sistema de balanza visual en torno a unos ejes imaginarios que estructuran la imagen y la compensan. Por su parte, la angulación apunta a un sentido tridimensional y de valor cualitativo, organizando esa materia filmable y desviando esos ejes de disposición espacial para generar un producto en el que predomine su carácter expresivo y emotivo ${ }^{21}$. Este poder jugar con la distancia, el enfoque, la cercanía, fue lo que separó la estética del cine de la del teatro, proponiendo un primer plano que rompía todos los esquemas escénico-teatrales y explorando toda su potencialidad semántica y dramática, además de poder decidir entre la representación "panorámica del cuadro, como el teatro, o los enfoques parciales y sucesivos para dar cuenta del conjunto, como la novela" 22 .

Composición y encuadre son esenciales para transmitir aquello que se pretende y hacer empatizar al espectador con lo que se muestra. El estudio del encuadre nos traslada principalmente al ámbito pictórico y toda una tradición histórica de cómo componer para una única imagen o instantánea. Una disciplina, la pintura, que ha servido como baluarte para la escenografía, y de la que se obtienen relaciones entre el sujeto propio de la obra, el material, sus capacidades narrativas, su tonalidad e iluminación, su espacialidad y perspectiva, o su posibilidad ambiental y de atmósfera. Por ello, la pintura y el cine se influyen y benefician recíprocamente dado que, como indica Cerrato, "para comprender mejor el cine, la vía de la pintura es a veces un paso importante. En el fondo se puede aún aceptar la definición godardiana: hacer cine significa ver con claridad en la caverna de Platón gracias a la luz de Cézanne"23.

Rafael Cerrato en su libro Cine y Pintura (2009) muestra estudios sobre las relaciones de ambas disciplinas, a cargo de diversos autores. Antonio Costa expone el concepto effetto dipinto, que a través de dos acepciones define, por medio de la pintura, un aspecto escenográfico de ambientación como effetto pitturato, y cuando el encuadre recuerda a una pintura o a su composición, iluminación, cromatismo u organización espacial, effetto quadro. De igual manera, muestra una

${ }^{20}$ VILA, Santiago: La escenografía: cine y arquitectura. Madrid, 1997, p. 32.

${ }^{21}$ BANDINI, Baldo y VIAZZI, Glauco: La escenografía cinematográfica. Madrid, 1959 , p. 40.

${ }^{22}$ BOBES, María Carmen: Estudios de semiología del teatro. Valladolid, 1987, p. 51.

${ }^{23}$ CERRATO, Rafael: Cine y pintura, op. cit., p. 51. 
tipología de intercambios en función de cómo se conciba la película pudiendo diferenciarse entre películas relacionadas con la representación pictórica (Passion, Jean-Luc Godard, 1982); películas sobre el trabajo de un pintor (Vincent y Theo, Robert Altman, 1990); películas históricas que utilizan fuentes pictóricas para recrear el clima (El gatopardo, Luchino Visconti, 1963); o películas donde la mirada y el retrato constituyen el motor de la narración (Laura, Otto Preminger, 1944). Por otra parte, Áurea Ortiz y María Jesús Piqueras ofrecen otra taxonomía, películas donde la pintura se utiliza como referente histórico, películas acordes a las vanguardias de principios del siglo XX y películas con cuadros, como objeto de atrezzo o como representación visual, tableau vivant.

Giorgio Tinazzi afronta la relación de la imagen cinematográfica desde la pintura como hecho funcional de descontextualización, como medio de construcción de la imagen y como articulación entre ambos lenguajes al provocar la autorreflexión a través de la pintura. François Jost aborda procedimientos para introducir la pintura en el cine, el cuadro como decorado (Los hijos de los hombres, Alfonso Cuarón, 2006); la narración como invocación de una pintura (Shirley: visiones de la realidad, Gustav Deutsch, 2013) o que la pantalla se convierta en un cuadro (Un americano en París, Vincente Minnelli, 1951). Y expone en común a los tres: "La intrusión de la pintura en el cine provoca siempre [...] una extrañeza: extrañeza representativa de la yuxtaposición del tiempo y de la eternidad, extrañeza narrativa de la mezcla del movimiento y de la pose, de la vida y de la muerte, incongruencia de una actitud desplazada: la de un cineasta que se toma por otro, el pintor"24.

Omar Calabrese realiza su estudio en referencia a la pintura como aporte para la construcción de la narración cinematográfica mediante analogías entre la pantalla y el cuadro, como fuente de motivos figurativos y como confrontación entre los tipos de narración. Y es que el significante pictórico o fílmico obra como repelente de su propia condición material además de ser la cara sígnica que ofrece e induce a la mirada a aquello que pretende representar y sea reconocido.

Esta influencia a la que se ve sometida el espectador depende en gran medida de la intención creativa del artista en una vertiente más naturalista -sin pretensiones semánticas más allá de lo que representa-, o por el contrario, expresionista -aparición de sentimientos propios del creador-. Pintores de la talla de Edvard Munch, George Grosz, Franz Marc o Egon Schiele tratan de provocar que todo exprese, no únicamente la figura humana o lo representado, sino el color, la composición, la pincelada, la propia materia. Y hasta el propio escenario natural en el caso cinematográfico puede actuar con una función dramática, haciendo de los cambios climáticos o fenómenos atmosféricos una expresión sentimental. Por ello, en Los sueños de Akira Kurosawa (Akira Kurosawa, 1990), "el

${ }^{24}$ JOST, François: "Le picto-film", en Ecritures et Arts Contemporains. Cinéma et peinture. Approaches. París, 1990, p. 121. 
calor remite a situaciones de contenido sexual y el frío a las de distanciamiento. La lluvia y el viento son los vehículos a través de los cuales las personas manifiestan sus emociones" 25 . Una película referente en este ámbito es Los nibelungos (Fritz Lang, 1924) en la que, desde su cartel (Figura 2), con reminiscencias al dorado simbolista, que inunda el cromatismo de la película y nos recuerda a estilos bizantinos o fondos utilizados por Gustav Klimt o Vittorio Zecchin, su vestuario y personajes evocan obras de John Singer Sargent, Carl Otto Czeschka, Fernand Khnopff y Jan Toorop, hasta el paisaje, parece transmitir su propia alma y ser un protagonista más, indispensable para la narración.

Multitud de películas podrían describirse donde la pintura hubiera formado parte en cualquiera de los diversos tipos de clasificación que hemos enumerado o como simple referente para la construcción de su propio universo, puesto que es inevitable obviar un recuerdo o evocación a una obra vista con anterioridad. En nuestro país, una gran cantidad de películas presentan conexiones con la pintura: Locura de amor (Juan de Orduña, 1948), El espíritu de la colmena (Víctor Erice, 1973), El rey pasmado (Imanol Uribe, 1992), Belle époque (Fernando Trueba, 1992), El sol del membrillo (Víctor Erice, 1992), Volavérunt (Bigas Luna, 1999), Te doy mis ojos (Icíar Bollaín, 2003), Óscar. Una pasión surrealista (Lucas Fernández, 2008), entre otras. Son cintas donde aparece el "efecto cuadro" o tableau vivant, citado para denominar la puesta en escena de una obra pictórica, o llevado al extremo contrapuesto como expresaba José de Manjarrés: "Una representación escénica no es más que una serie de cuadros animados: y todo debe estar colocado dentro del marco, que es la boca del escenario"26. Estas recreaciones buscan interrumpir la linealidad temporal de la trama, haciendo una reflexión sobre lo mostrado o un homenaje al autor nombrado. Uno de los más notables tableau vivant de la historia del cine español lo acomete Luis Buñuel con Viridiana (1961) (Figura 3), trasponiendo La última cena (1495-1498) de Leonardo da Vinci y haciendo una mescolanza de influencias de Goya y Gutiérrez Solana.

Fuera del territorio nacional, el "efecto cuadro" hace presencia en la pantalla en un sin fin de ejemplos: Barry Lyndon (Stanley Kubrick, 1975) con referencias a Constable, Vermeer, Reynolds; La marquesa de $O$ (Eric Rohmer, 1976) apuesta por Füssli; Passion (Jean-Luc Godard, 1982) lo hace con Rembrandt, Goya, Ingres; Avatar (James Cameron, 2009) refleja a Roger Dean. En el caso de Los sueños de Akira Kurosawa se trasciende en ocasiones el efecto tableau vivant apareciendo en la segunda historia una distribución de figuras en hilera que ante la poca profundidad de campo imprime la sensación de "la representación viviente de un lienzo", así como en las escenas en las que se muestran El puente de Anglois en Arlés sobrepasando el efecto cuadro y generando que la realidad y la ficción

${ }^{25}$ CAMARERO, Gloria: Pintores en el cine..., op. cit., p. 229.

26 ARREGUI, Juan: Los arbitrios de la ilusión: los teatros del siglo XIX ..., op. cit., p. 324. 
se confundan, y cuando el estudiante ya disfruta de recorrer los propios paisajes pintados por Van Gogh siendo la viva estampa del cuadro en movimiento ${ }^{27}$.

Toda esta serie de "efectos pictórico-visuales" los dispone el director para hacer creer lo que se observa, y crear un desdoblamiento de lo real ante la realidad fingida. Esto es lo que pretende producir y provocar el trompe l'oeil con su engaño a la visión y su ardid en el artificio. A continuación, nos adentramos en el mismo con la intención de distanciarnos de su astucia para definirlo y entenderlo.

\section{EL TROMPE L'OEIL: FALSA EVIDENCIA EN LA PINTURA Y EL CINE}

El relato de Hans Christian Andersen El traje nuevo del emperador (1837) narra la historia de un rey que quedó humillado ante su pueblo por su orgullo y vanidad, y nos traslada la moraleja de que no es real todo lo que la mayoría piensa que es verdad. Quizás el acto de "ver para creer" de Santo Tomás ante la resurrección de Cristo, introduciendo sus dedos en la llaga de su costado, nos traslade completamente a la esencia de la narración, a un acto de fe ante lo desconocido. Este es el punto de inflexión del que partiremos para definir y entender el trompe l'oeil, o trampantojo.

Muchas son las leyendas que cuentan las hazañas producidas por la pintura en su afán de travestirse como la realidad misma. De ahí, la promulgada por Plinio el Viejo donde una doncella dibujó la silueta de la sombra del rostro de su amado, proyectada sobre la pared, para disfrutar de él durante su ausencia (Figura 4); o aquella de un pintor chino que, ante la retención a la que fue obligado para estar en el palacio del emperador, pintó un paisaje con tanta exactitud que se introdujo en él y se perdió en su horizonte -como el caso mencionado del estudiante en Los sueños de Akira Kurosawa, premonición de nuestra realidad virtual-; o la que contaba Giorgio Vasari entre Giotto y su maestro Cimabue, pintando el aprendiz una mosca tan realista que el maestro trató de ahuyentarla en varias ocasiones; o la célebre disputa entre los pintores Zeuxis y Parrasio que, intentando dilucidar cual de los dos era mejor, celebraron un concurso, logrando el primero engañar con unas uvas el ojo de los animales, mientras que el segundo, con una cortina hizo lo propio con el ojo de su oponente. Para el psicoanalista Jacques Lacan este hecho exponía que mientras los animales se sentían atraídos por las apariencias superficiales, los humanos se veían seducidos por la idea de lo oculto.

Este "estar oculto" hace del ojo y la mirada la pareja perfecta, que juega la dialéctica del deseo. Existe un apetito visual, un hambre en el ojo por ir más allá. $Y$ es el deseo el que se infunde como fuerza penetrante, ya que "la mirada solo se interpone en la medida misma en que el que se siente sorprendido por la misma,

${ }^{27}$ CAMARERO, Gloria: Pintores en el cine..., op. cit., pp. 232-234. 
no es el sujeto anonadante correlativo del mundo de la objetividad, sino el sujeto que se sostiene en una función de deseo" ${ }^{28}$. Un término deseo, abordado por teóricos como Tomás de Aquino, que lo definió no solo como un apetito sensitivo sino como la aspiración por algo que no se posee; Descartes lo expresó como una agitación del alma; para Locke, como la ansiedad que surge de la ausencia de algo; para Spinoza es el apetito acompañado por la conciencia misma; y para Hegel, la conciencia de sí mismo; o desde un punto de vista psicoanalítico como una pulsión de vida. Un deseo que se produce en la pintura como revelación de un sentimiento de confusión y distorsión de la realidad, llevado al exceso de la representación, en un enredo o artificio que provoca una "trampa ante el ojo".

El nacimiento del trampantojo, según Flaminio Gualdoni, se debe al cambio de mentalidad que produjo el cruce de la perspectiva italiana del siglo XV y del arte flamenco ${ }^{29}$, provocando un placer similar al que obtenemos hoy con la realidad virtual. Variedad de artificios se realizaban para hacer de la pintura una veladura de la realidad, como elogiaba el padre de Rafael, Giovanni Santi, a Andrea Mantegna "porque asombra a quienes ven y admiran sus escorzos, que el ojo engaña y son regocijo del arte", según cita Gualdoni. Como en su tan conocida Lamentación sobre Cristo muerto (1470-1474), a la que se referencia en la película de Ray Loriga, Teresa: el cuerpo de Cristo (2007) o la de Albert Serra, La muerte de Luis XIV (2016) (Figura 5), colocando al Rey Sol como Cristo en una iluminación que Rembrandt acogería como totalmente personal.

Creer, esa es la palabra. Mediante una estrategia conseguir en el destinatario que crea en lo que sucede ante él, es la intención superior a lo que aspira el trompe l'oeil. Como denomina Severo Sarduy es una declinación de los sentidos: "La vista renuncia, el tacto tiene que venir a comprobar, y a desmentir, lo que la mirada, víctima de su ingenuidad, o del puntual arreglo de un artificio, da por cierto: la profundidad simulada, el espacio fingido, la perspectiva aparente, o la excesiva, y por ello sospechosa, compacidad de los objetos, la insistente nitidez de sus contornos, la arrogancia de las texturas" 30 .

La representación se desvanece con un simple desplazamiento de la mirada haciéndonos notar que su apariencia no se desplaza con nosotros y viene a convertirse en otra cosa de lo que pretendía ser. La pintura rivaliza con la verdad, no con la apariencia, aquello que Platón designaba como Idea, ya que el universo al que entramos se desintegra, se rompe la relación aprendida entre el objeto y el yo en esa tierra intermedia, entrando en juego los términos "probabilidad" y "distancia", analizados por Jean Paul Sartre en El ser y la nada (1989). Ese hacerse pasar por el referente excluyendo cualquier residuo en su trasposición hace

${ }^{28}$ LACAN, Jacques: Los cuatro conceptos fundamentales del psicoanálisis. Seminario 11. Buenos Aires, 2008, p. 92.

${ }^{29}$ GUALDONI, Flaminio: Trampantojo. Milano, 2008, p. 13.

${ }^{30}$ SARDUY, Severo: La simulación. Caracas, 1982, p. 41. 
de él la incuestionable tarea de la negación de cualquier interferencia estilística y técnica, no pudiendo dejar, el artista o creador, nada dado a la imaginación. Se constituye como un juego haciendo de una superficie plana toda una tridimensionalidad bajo la habilidad y destreza técnica, desencadenando un agujero en su propia identidad, ya que no pretende contar una historia, sino serla en sí misma, escenificándola. El trampantojo pretende "duplicar la realidad en la imagen, llegando a veces hasta lo hipertrófico de la precisión, a la simulación milimétrica, o al despilfarro de los detalles; el ejecutante del trompe l'oeil como un demiurgo secundario, envidioso y maniático, delimitada a esta perversión su práctica" ${ }^{31}$. Un ejecutante que ha tenido siempre grandes detractores que han tildado su actuación de imitación sin valor, desprovista de pasión, donde la fotografía lo suple con muchas más garantías y cuyo único encanto es su carácter engañoso.

Pero, en realidad, su funcionalidad en las primeras décadas del cine, era precisamente esa, prestar un engaño a la acción y no ser descubierto -el decorado pintado- para no producir una escisión en la realidad, en la conciencia, y no dando la oportunidad a un escrutinio más pormenorizado de la mirada, originando ese desplazamiento que mencionábamos y dejando al descubierto el intento de ilusión. Una ilusión que pretende revelar una dualidad de dos mundos: el de lo representado y el que contiene a la representación, el de la ausencia y el de la presencia, el de la semejanza y el del espejismo, enfrentando al espectador "con su deseo, es decir, con el deseo de que haya algo y no nada, al tiempo que le demuestra que algo y nada se dan de manera simultánea en la emergencia escandalosa del simulacro"32. Así, el trompe l'oeil muestra a la vez que esconde, poniéndonos en la tesitura de si creer o no.

Surge paralelamente al trampantojo otro término, muy vinculado a la definición de este último, aunque su existencia es mucho más reducida, exacta y complicada: la anamorfosis. Creada a partir de un procedimiento óptico, se basa en una falsa medida, en una realidad trucada, donde al igual que en el trampantojo la representación se desdobla, busca un único punto de vista que la haga funcionar, para generar confusión y desconcierto. $\mathrm{Y}$ es que para Bonitzer, el cine establece una relación con estas dos prácticas pictóricas fundamentales para la imagen cinematográfica: "El engaño, la falsa evidencia y su correlato ambiguo, la figura del desmentido, son los elementos fundamentales del cine. [...] El cine es por definición una máquina ilusionista. Se relaciona con la pintura justamente a través del trompe l'oeil. ¿Es el trompe-l'oeil el denominador común entre el cine y la pintura, el plano y el cuadro? Si el cine ha sido despreciado como arte durante mucho tiempo ha sido justamente por su carácter de atracción ilusionista

\footnotetext{
${ }^{31}$ Ibidem, p. 46.

32 BONITZER, Pascal: Desencuadres: cine y pintura ..., op. cit., p. 71.
} 
para uso de las masas [...]. El trompe l'oeil es lo primero que el cine solicita a la pintura" 33 .

Por tanto, el trompe l'oeil marca una delgada línea de separación entre la realidad y el simulacro siendo "una suerte de inversión metafísica, de trasgresión interna, de subversión de la norma realizada en secreto, mediante un agujero en la realidad [...]. Es la inexistencia de la realidad, el secreto de la reversibilidad, siempre factible, del espacio real" ${ }^{34}$. Quizás después de todo esto, cada uno deba preguntarse: ¿Es una seducción la que produce, un deseo, un cautiverio o un regocijo?

\section{PINTOR-PINTOR VERSUS PINTOR-CINEMATOGRÁFICO}

Quisiéramos aclarar que ante nuestra intención de comparar estas dos posibles figuras y aún conociendo las denominaciones de "pintor escenográfico" -procedente del ámbito teatral-y "maquetista" -no contempla en su nombre la palabra pintor y no refiere su trabajo a una labor manual específicamente pictórica, aunando construcción de decorados, maquetas y efectos especialesproponemos la de "pintor cinematográfico" por el cambio radical que supone el punto de vista fílmico y el no tener que pintar para el ojo humano sino para el "ojo" -objetivo- de la cámara.

La figura del pintor ha ido evolucionando a lo largo de los años desde la disyuntiva de artesano en la Edad Media hasta la de artista en la actualidad, su consideración como profesión en el Barroco, su concepción general por parte de la sociedad como persona bohemia, sin una labor fundamental para la comunidad, hasta la cosificación que sufre hoy día ante la apabullante cadena de consumo, superproducción y competitividad. El "pintor-pintor" -artista- hoy traduce la realidad según sus emociones, conocimientos y actitud crítica, haciendo uso de sus capacitaciones técnicas y conceptuales. Su obra es claro reflejo de sus señas de identidad. El trabajo del "pintor cinematográfico", en cambio, queda camuflado, al puro estilo del trampantojo. Únicamente durante el expresionismo gozó de cierta libertad en la composición de los fondos haciendo de ellos puros cuadros que acompañaban a la acción, como en El gabinete del doctor Caligari (Robert Wiene, 1920) (Figura 6). Considerado pintor de fondos o maquetas en el cine no puede llegar a tal extremo, puesto que separaría la ficción de la pintura de la realidad, el observador notaría esta dualidad y se revelaría la acción del pintor como cómplice del engaño. Sin embargo, el trabajo del pintor-pintor se basa fundamentalmente en trabajar con la memoria, con el recuerdo, con la retentiva, aunque se

${ }^{33}$ ORTIZ, Áurea y PIQUERAS, María Jesús: La pintura en el cine..., op. cit., p. 27.

${ }^{34}$ BAUDRILLARD, Jean y CALABRESE, Omar: El trompe-l'œil. Madrid, 2014, pp. 36-37. 
tenga el modelo justo delante. David Hockney proclamaba este acto como una fundamentación en niveles o capas: "Los pintores no se limitan a añadir pintura y más pintura sobre un lienzo o un papel, sino que las ideas nacen una tras otra, ajustándose a la anterior, al igual que el trabajo de observación [...], gran parte de la experiencia humana, si nos detenemos a reflexionar sobre ello, funciona a base de capas o niveles. Entendemos el presente comparándolo con el pasado [...] nuestro ángulo de visión va cambiando" ${ }^{35}$.

En esta comparación del presente con el pasado, comenzaremos por el más antiguo, por la figura del pintor en el ámbito teatral. Este profesional era definido por Francisco Arola, en las primeras décadas del siglo XX, como "pintor escenógrafo" y que tenía como función la preparación de los escenarios para las diversas representaciones. Estos pintores realizaban sus tareas artísticas principalmente sobre forillos o cicloramas - también llamado panorama-y en rompimientos, orillas, techos o fondillos.

Por su parte, en el ámbito cinematográfico, los pintores, que procedían del teatro y llevaban consigo las tareas escenográficas, tuvieron que adaptarse al nuevo medio y conocer una serie de nociones acerca de la cámara, los objetivos y los resultados que se obtenían en celuloide. El tener la proximidad del ojo del espectador hasta un primer plano hacía que la tarea más artesana de falsear muros mediante pátinas de mármol, de madera u otros materiales fuera muy delicada a fin de evitar que el espectador percibiera lo representado como apariencia. En los inicios del cine, el pintor se encargaba de crear la profundidad por medio de luces y sombras sirviéndose solo de la pintura, pasando más adelante a los trucos visuales como el Glass Shot o Matte Painting -muy empleados en grandes superproducciones de ciencia ficción actuales-, combinando la realidad con construcciones y pinturas. El papel de los pintores no se limitaba al trabajo anterior al rodaje, sino que durante el mismo podían requerir de sus servicios para subsanar errores o problemas que fueran surgiendo. Christian Bérard habla de la importancia del pintor en un proyecto cinematográfico y cuáles deberían ser sus funciones: "No hay que limitar el papel del pintor a una simple decoración, reducirle a dibujar un fondo para los actores. En lugar de dedicarse a un trabajo práctico, el pintor debe ser llamado a tomar parte activa en ese trabajo de colaboración que es la composición y la realización de una película"36.

Esta remarcable tarea del pintor, lo expone a un nivel de responsabilidad y exigencia que va más allá de la sola labor manual. Emilio Ruiz del Río (19232007) pintor, decorador, maquetista, miniaturista y director artístico, ha sido máximo exponente que ha liderado este tipo de profesional en el ámbito nacional. $\mathrm{Su}$ especialidad en la consecución de efectos visuales, utilizando la pintura sobre

${ }^{35}$ HOCKNEY, David: David Hockney: el gran mensaje. Conversaciones con Martin Gayford..., op. cit., p. 115.

${ }^{36}$ ORTIZ, Áurea y PIQUERAS, María Jesús: La pintura en el cine..., op. cit., p. 48. 
cristal así como las maquetas y miniaturas, también tuvo un reconocimiento internacional. Su vida profesional estuvo muy vinculada a la figura del también pintor y director de arte Enrique Salvá durante más de diez años, comenzando como ayudante de este aprendiendo la técnica de pintar forillos. Ruiz del Río se convirtió en el artífice de lo posible, de la mentira y la simulación, dentro de un amplio espectro de alternativas que ejecutaba con genialidad y una imaginación desbordante para hacer de lo estático e inmóvil, algo de apariencia viva y natural. De una credibilidad excesiva y apabullante sus trucos y maquetas aparecían ante la mirada atenta de los espectadores como realidades existentes filmadas in situ, como si su mano no hubiera hecho acto de presencia en esa imagen y con la dificultad de poder diferenciar lo ficticio y construido de lo real y presente. Tan perspicaces eran sus creaciones que él mismo exponía: "los trucajes eran tan buenos que ni los académicos los distinguían al ver la película" ${ }^{37}$. Ray Harryhausen compartió gran cantidad de proyectos junto a Ruiz del Río y, a pesar de su creatividad en el ámbito de los efectos especiales y la animación de stop motion, quedó fascinado por el trabajo de este, como se expone en el documental El último truco. Emilio Ruiz del Río (Sigfrid Monleón, 2008).

En relación a la técnica que utilizaba a la hora de pintar los cristales y crear una apariencia de realidad (Figura 7), Ruiz del Río expone: "Lo primero es utilizar unas ópticas angulares y situar la cámara a unos tres metros y medio del cristal. Después hay que iluminar muy bien el cristal para que tenga la misma luz que el decorado. Por último, y esta es la parte difícil, es necesario realizar un tipo de pintura que está a medio camino entre el impresionismo y el expresionismo. [...] El peligro de este tipo de pintura a medio hacer es que le falte fuerza y el resultado sea soso y deslavazado, carente de interés. Para remediarlo, Salvá y yo hacíamos lo mismo que en los forillos, darle a las sombras el doble de grosor del que le daríamos en, por ejemplo, un cuadro al óleo. De este modo, la imagen ganaba en rotundidad y lucía muy bien" 38 .

La utilización de un cristal delante de la cámara precisaba de un fondo negro para eliminar los numerosos reflejos que recoge -el cristal- (Figura 8). Sobre este plano vertical, el pintor va tomando puntos de referencia para el encaje, ayudándose de mirar por el visor de la cámara para ir delimitando la silueta del espacio a pintar. Una vez realizado, el pintor aplica una pintura de base de fuerte adherencia al cristal, y tras su secado pasará a marcar los puntos de fuga, sirviéndose del fondo real. Establecida la hora del rodaje, para tener localizada la dirección de la luz, comenzará a encajar el color igualándolo con el del fondo, así como aproximándose a las luces y las sombras, disponiendo de un período de una hora

${ }^{37}$ SANDERSON, John y GOROSTIZA, Jorge: Constructores de ilusiones: la dirección artística cinematográfica en España. Valencia, 2010, p. 110.

38 Ibidem, p. 112. 
durante el cual poder pintar ${ }^{39}$. En este trabajo, el pintor tantea como un ciego en la oscuridad intentando captar el momento exacto y la luminosidad precisa en un alarde de impresionismo, y gozando de una gestualidad que no haga de la pincelada algo aburrido y sin vida, en un sentido expresionista, como el propio Ruiz del Río declaraba. Y es que en estos casos, hay que escoger una luz, un instante, y hacer de ello una creencia, al modo de lo que exponía Picasso: "Si no tienes rojo, usa el azul. Haz que el azul parezca rojo" ${ }^{40}$.

\section{CONCLUSIONES}

Nuestra investigación desprende tres conclusiones principales. La primera desvela que la pintura ha estado al servicio del cine influenciándose recíprocamente y manteniendo estructuras de creación de la imagen. La segunda conclusión muestra que el trompe l'oeil o trampantojo y la desaparición de la huella humana en estas pinturas cinematográficas busca declinar los sentidos del espectador y proporcionar un engaño que haga de la imagen una realidad propia en la pantalla. Finalmente, la tercera conclusión subraya que el pintor-cinematográfico, como alma mater, se configura como un "mago" ante el ojo de la cámara para hacer de su trabajo un acompañamiento no solo escenográfico-ambiental sino también de significado.

Fecha de recepción: 27 de octubre de 2017

Fecha de aceptación: 12 de abril de 2018

${ }^{39}$ RUIZ DEL RÍO, Emilio: Rodando por el mundo: mis recuerdos y mis trucajes cinematográficos. Madrid, 1996, pp. 31-32.

40 HOCKNEY, David: David Hockney..., op. cit., p. 98. 


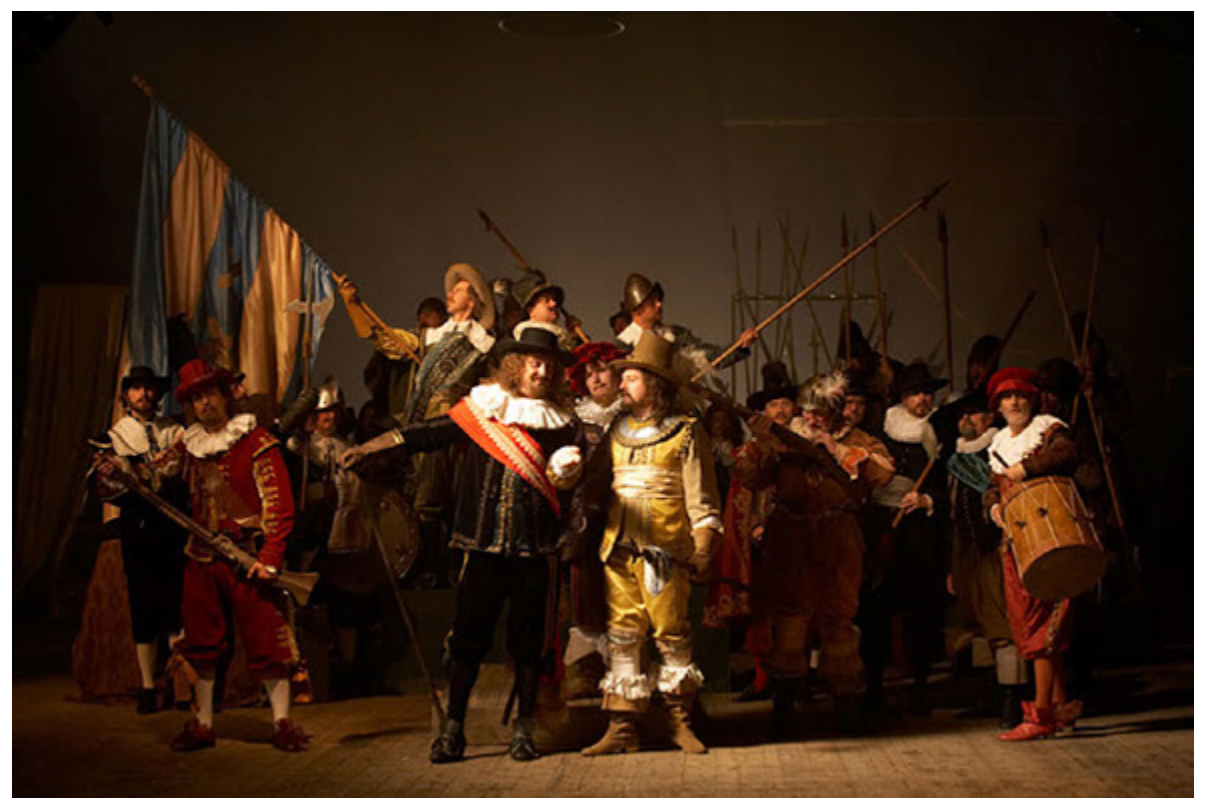

Figura 1. Peter Greenaway, La ronda de noche, 2007. Fuente: https://www.youtube.com/watch?v=JN2eLySBIMc 


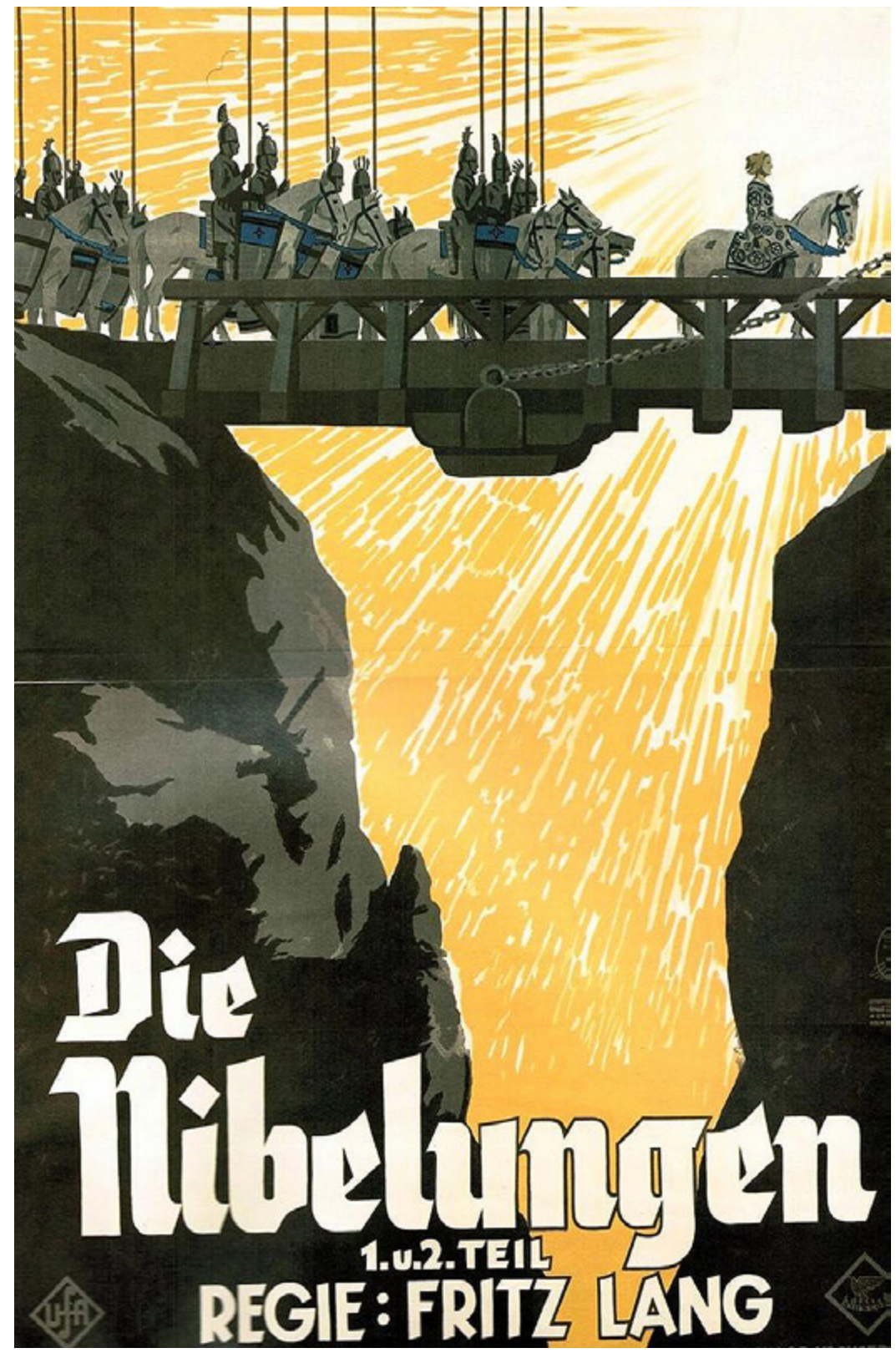

Figura 2. Fritz Lang, Los nibelungos:

La venganza de Krimilda (cartel), 1924.

Fuente: http://www.filmaffinity.com/es/film666625.html 


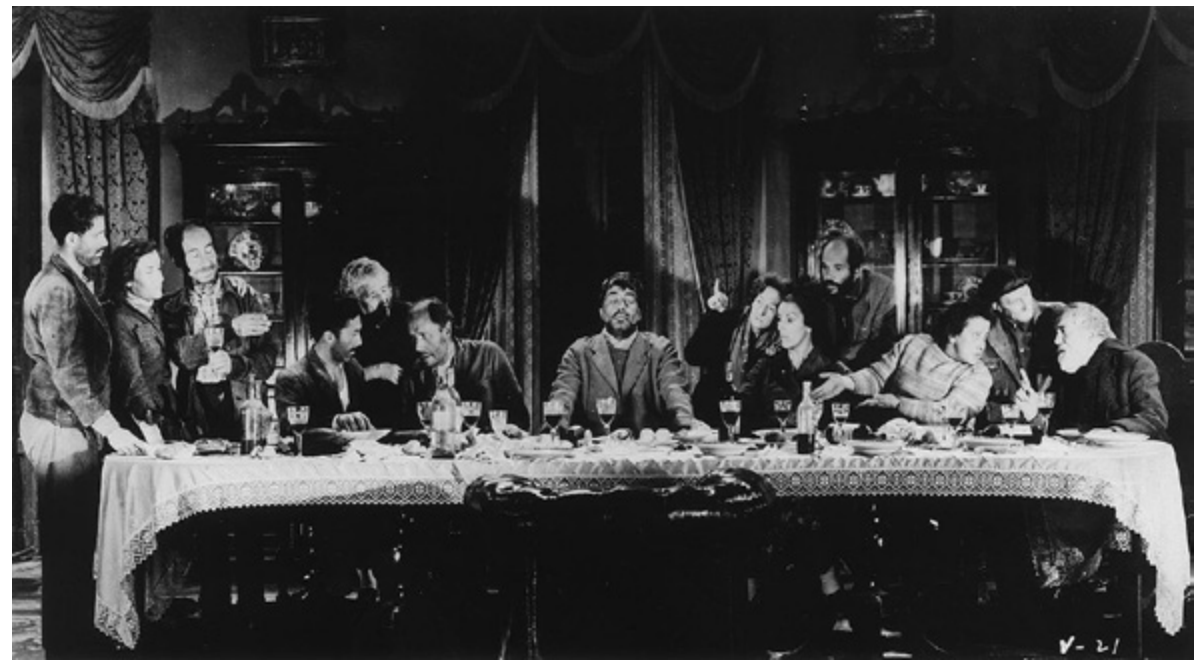

Figura 3. Luis Buñuel, Viridiana, 1961.

Fuente: http://comerbeberamar.blogspot.com.es/2010/04/bunuel-viridiana.html

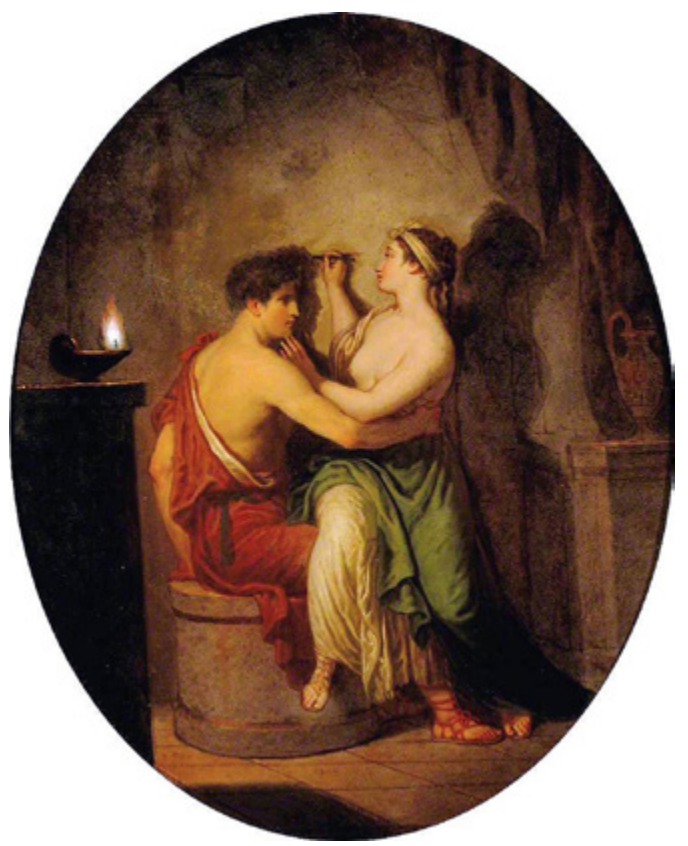

Figura 4. David Allan, The Origin of Painting, 1775. Óleo sobre tabla, 38,7 x $31 \mathrm{~cm}$. Fuente: http://www.the-athenaeum.org/art/full.php?ID=163734 


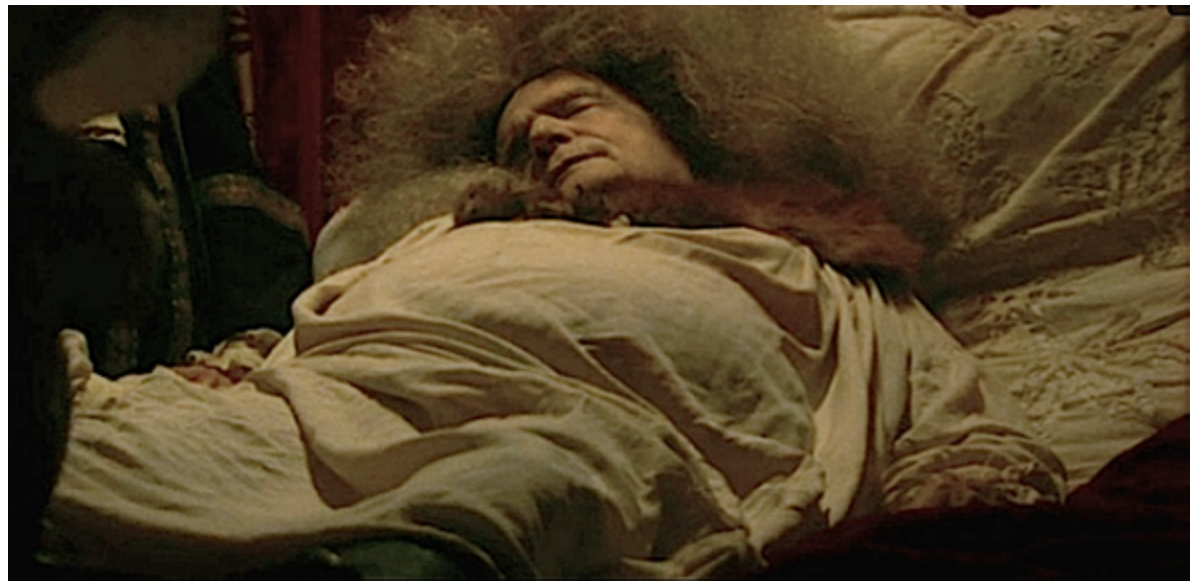

Figura 5. Albert Serra, La muerte de Luis XIV, 2016.

Fuente: http://www.dailymotion.com/video/x595a4v

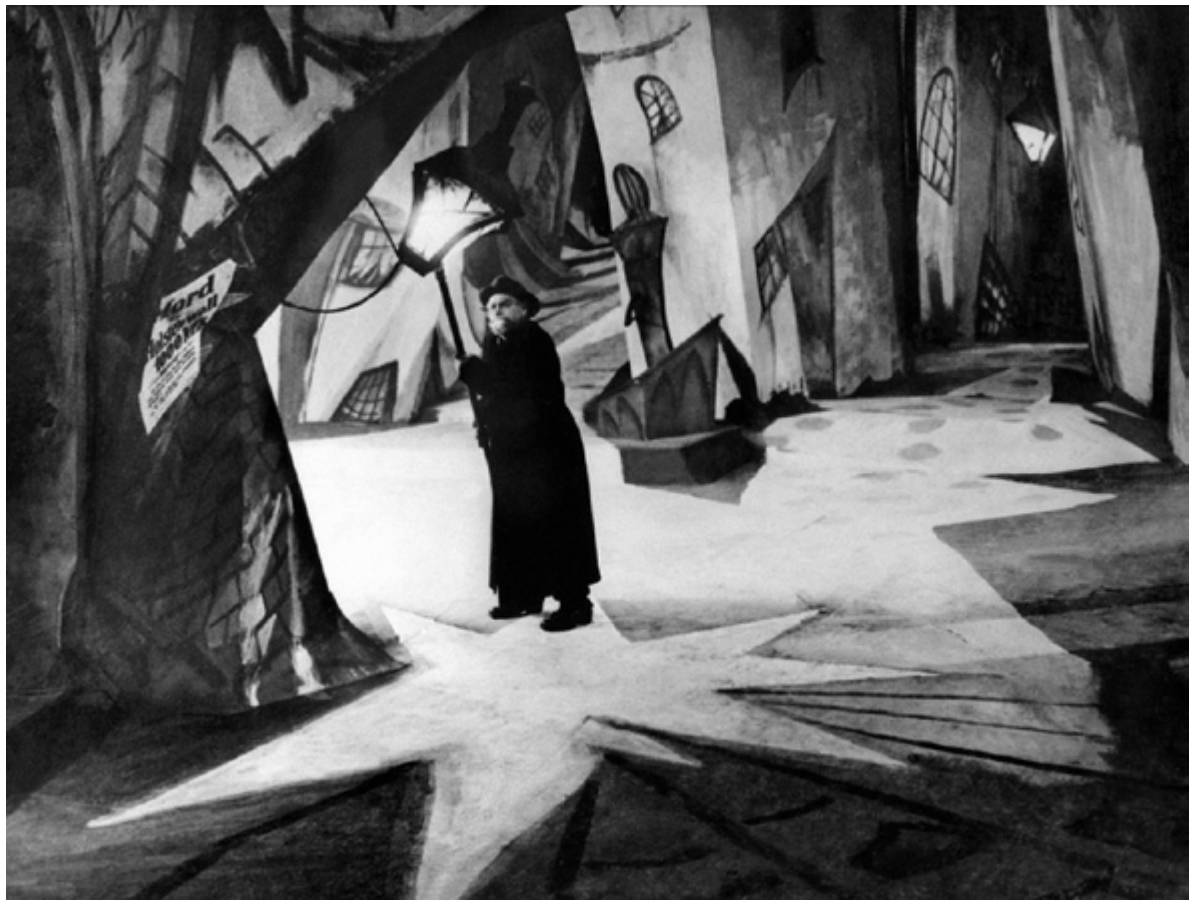

Figura 6. Robert Wiene, El gabinete del doctor Caligari, 1920.

Fuente: https://gmasaarquitectura.files.wordpress.com/2013/01/dr-caligari.jpg 


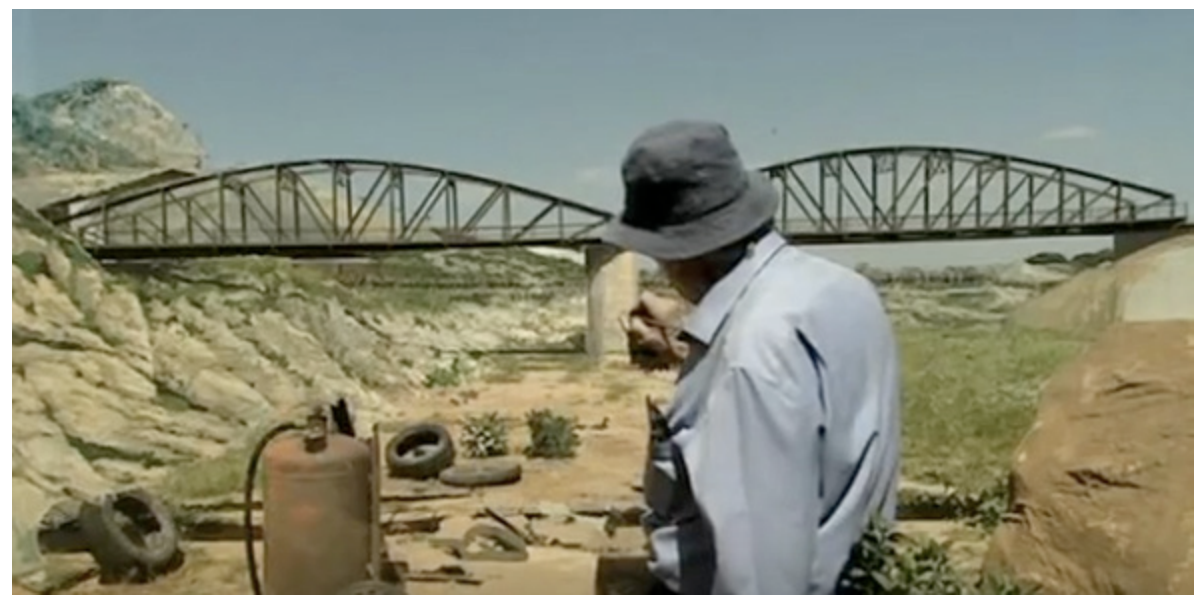

Figura 7. Sigfrid Monleón, El último truco. Emilio Ruiz del Río, 2008.

Fuente: https://www.youtube.com/watch?v=LPKiviAm2kQ

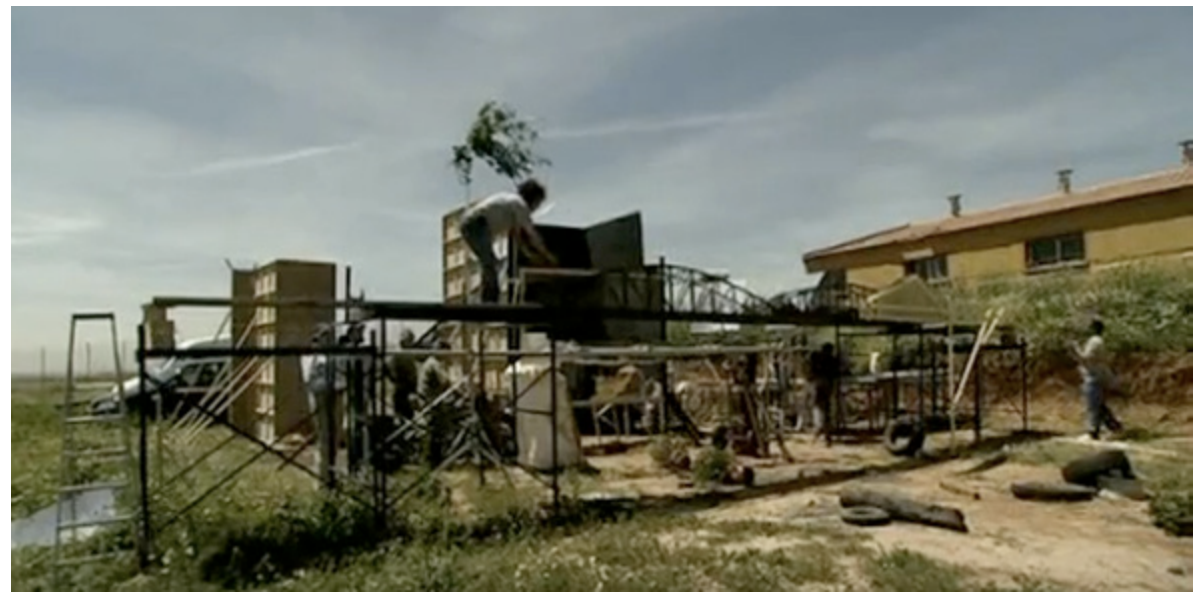

Figura 8. Sigfrid Monleón, El último truco. Emilio Ruiz del Río, 2008.

Fuente: https://www.youtube.com/watch?v=LPKiviAm2kQ 